Brit. J. industr. Med., 1964, 21, 235.

\title{
STANNOSIS IN HEARTH TINNERS
}

\author{
BY \\ C. W. D. COLE, J. V. S. A. DAVIES, M. D. KIPLING, and G. L. RITCHIE \\ From Heath Lane Hospital and Hallam Hospital, West Bromwich, and \\ H.M. Inspector of Factories
}

(RECEIVED FOR PUBLICATION DECEMBER, 12 1963)

\begin{abstract}
There have been no published reports of stannosis in tinners. In this paper its occurrence in hearth tinners is described.

In hearth tinning molten tin is poured into heated iron hollow-ware and smoothed over the internal surface with a cork bat. Ammonium chloride powder is used as a flux. It is considered that fumes arising in the.process from the reaction of the flux and the tin caused a concentration of tin compounds in the atmosphere, and this was the mechanism by which stannosis was produced.
\end{abstract}

The literature on stannosis and tinning is reviewed.

The process of hearth tinning of iron hollow-ware, which has recently been discontinued in West Bromwich owing to the lack of skilled tinners, was carried out over coke hearths situated against an outside wall of the workshop. Molten tin was poured from a container into heated iron hollowware pots, and ammonium chloride powder was used as a flux. The hollow-ware was held by tongs and swirled round to spread the tin evenly on the surface, and the excess tin was poured from pot to pot. The final spreading was done with a cork bat, a triangular piece of cork on a handle. A skilled workman in this manner could tin up to 150 saucepans a day using approximately $50 \mathrm{lb}$. $(23 \mathrm{~kg}$.) of tin a week.

Fumes arose during the pouring of the tin and the use of the bat. The only exhaust ventilation was provided by a brick chimney through which the fumes escaped by heat convection. Elsewhere in the large shops in which hearth tinning was carried out the cast utensils were first sand (and latterly shot) blasted and then fettled.

\section{Historical Review}

The history and technique of tinning have been reviewed by Whymper (1888) and by Hedges (1960). The art of coating metal with tin was known to the Romans, and tinning of iron has been carried on in this country since the tenth century. Spurs of this date were tinned by dusting the metal or a lead-tin alloy on to the iron before it was heated (Jope, 1956). The tin plate industry started in the fourteenth century in Bohemia and spread to Saxony, whence it was brought to Britain in the latter half of the seventeenth century, when the craft was recognized by the grant of a Royal Charter; but the tin plate industry did not develop on a large scale until 1730.

Most tin-plating is now done by electro-deposition, some by spraying or chemical deposition, but about a quarter of all tin-plating is still carried out by hot dipping. This method is used for a variety of objects other than tin plate and is one in which the skill and experience of the operator is of great importance.

The properties of tin that have led to its adoption as a metal covering are its low melting point, $232^{\circ} \mathrm{C}$., its high fluidity, and its power of wetting and adhering to other metals in a film that in hot dipping may be as thin as 0.0075 in. $(0 \cdot 1905 \mathrm{~mm}$.). To aid the application of the tin, fluxes are used, such as palm oil, tallow, ammonium chloride, and zinc chloride, and to the latter may be added proportions of ammonium, sodium, potassium, lithium, and stannous chloride.

The flux may be applied to the metal either by preliminary dipping in a bath of flux, by passing it through molten flux on the surface of the tin bath, or by a combination of these methods.

The literature relating to the toxicity of tin has been reviewed by Browning (1961). Pulmonary changes in an enamel worker were first described by Beintker (1944) and attributed to the inhalation of 
tin oxide. Pendergrass and Pryde (1948) described a benign pneumoconiosis in a man who had been employed for 15 years on bagging tin oxide, recovered chemically from tin cans. Barták, Tomečka, and Tomiček (1948) described seven cases of stannosis attributed to fumes from a furnace converting tin to stannic oxide. Tin was found in the lungs at necropsy in one case. Cutter, Faller, Stocklen, and Wilson (1949) described radiological changes in two men grinding, calcining, and packing tin oxide in a scrap metal recovery plant. Dundon and Hughes (1950) described a case in a worker on a de-tinning furnace and gave a report on the pathology and analysis of the lung. They considered furnace fume was the most important source of stannic oxide. Spencer and Wycoff (1954) reported benign tin oxide pneumoconiosis in a smelter and bagger of tin oxide who had been exposed for 22 years.

Robertson and Whitaker (1955) found that out of 215 workers in a tin smelting plant, 121 showed radiographic changes. Oyanguren, Haddad, and Maass (1958) reported on environmental studies at a tin smelting plant. Robertson, Rivers, Nagelschmidt, and Duncumb (1961) reported on the clinical, radiological, and pathological findings in workers with abnormal radiographs in a tin smelting works. They found no evidence of symptoms attributable to stannosis. Radiographs showed nodular opacities 3 to $5 \mathrm{~mm}$. in size, with no significant pulmonary fibrosis and no evidence of silicosis. Macroscopically a whole lung section showed dust foci distributed uniformly throughout the lung, but no silicotic or fibrous nodules were seen. On microscopical examination the dust foci were found to consist of dense aggregates of dustladen macrophages surrounding the respiratory bronchioles. No extracellular dust and no dilatation of the lymphatics were seen. Chemical and $x$-ray diffraction analysis showed that tin was present in the lung, and $x$-ray emission micro-analysis demonstrated tin in a lung phagocyte. In a discussion on the origin of the tin oxide the authors said that exposure of the patient to tin oxide of respirable size in sufficient quantity will give the diagnostic radiographic appearances whether the source be fume or dust.

\section{The Survey}

A review was made of workers with stannosis recorded in this district. These numbered 10 in all. Cases 1, 5, 7, and 8 had been diagnosed as inpatients at general hospitals in the area. Cases 2, 9, and 10 attended a local chest clinic, and cases 3, 4, and 6 came to light as a result of our enquiries. It was found that all had worked at one or other of two factories in which hearth tinning was done. These 10 men were the only ones who were known to have worked on hearth tinning at these two factories; all 10 were found to have stannosis. We consider that the staff or employees would certainly have recollected and told us if any other hearth tinners had been so employed.

Radiography.-The films were reported upon by Dr. A. O. Bech, who considered that all showed changes due to stannosis. He reported on the films in accordance with the 'Classification of Radiographs of the Pneumoconioses' as suggested by the Convention of Geneva held by the International Labour Office in 1958.

\section{Clinical Investigations}

Case 1.-H.P. aged 75 was apprenticed as a hearth tinner at the age of 13 and continued in the trade for 61 years. In 1957 he was admitted to hospital for three weeks with pneumonia. In 1963 there were no abnormalities on clinical examination.

The report on the chest radiograph taken on May 1, 1957 (Fig. 1) is as follows: 'Shows profuse and very opaque micronodular opacities evenly distributed over both lung fields; resolving pneumonic infiltration is superimposed in the right lung field, which involves the posterior segment of the upper lobe and basal segments of the lower lobe. The hilar shadows are opaque. Classification: $\mathrm{m} 3$ (+ resolving pneumonic infiltration).'

Case 2.-J.D. aged 70 worked as a hearth tinner for 44 years. He then worked as a labourer and watchman for 11 years with no exposure to dust or fume. He was fit all his life until he suffered from bronchitis in 1962. On clinical examination in 1963 he had a slight degree of chronic bronchitis.

A chest radiograph taken on October 3, 1963 was reported upon as follows: 'Shows opaque hilar shadows and opaque punctate opacities evenly distributed over both lung fields' Classification: p.3.'

Case 3.-J.A. aged 70 worked as a hearth tinner for 55 years until he retired at the age of 68 . In 1963 he gave no history of illness, and physical examination revealed no evidence of intrathoracic abnormality.

The following is a report on the chest radiograph taken on October 2, 1963: 'Shows punctate opacities distributed over both lungs, but most evidence in the upper and mid zones. Hilar shadows are dense. The left diaphragm is elevated and partially obscured by pleural thickening. Classification: p.3.'

Case 4.-J.Y. aged 58 was apprenticed as a hearth tinner and continued this work for 16 years. He then worked as a hot dip tinner, for the first nine and a half years using tallow as a flux and for the last 13 years 


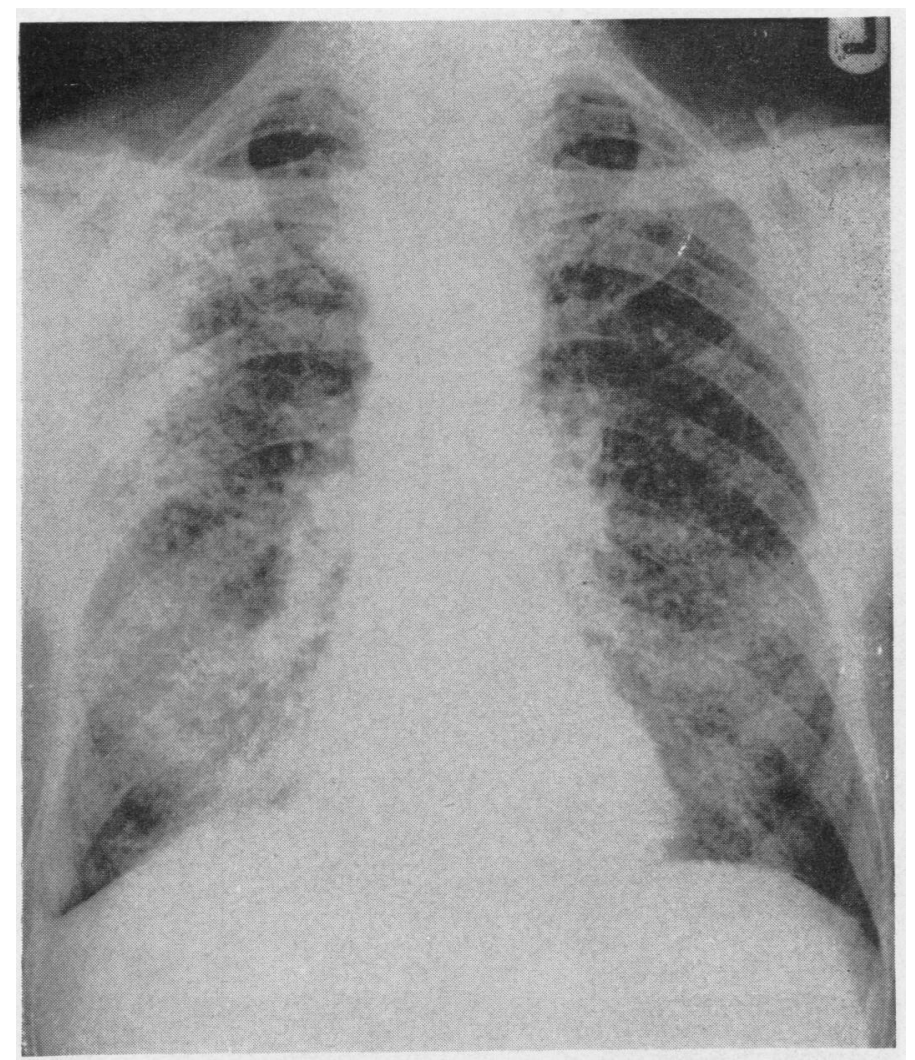

Fig. 1.-Case 1, May 1957, 61 years' exposure.

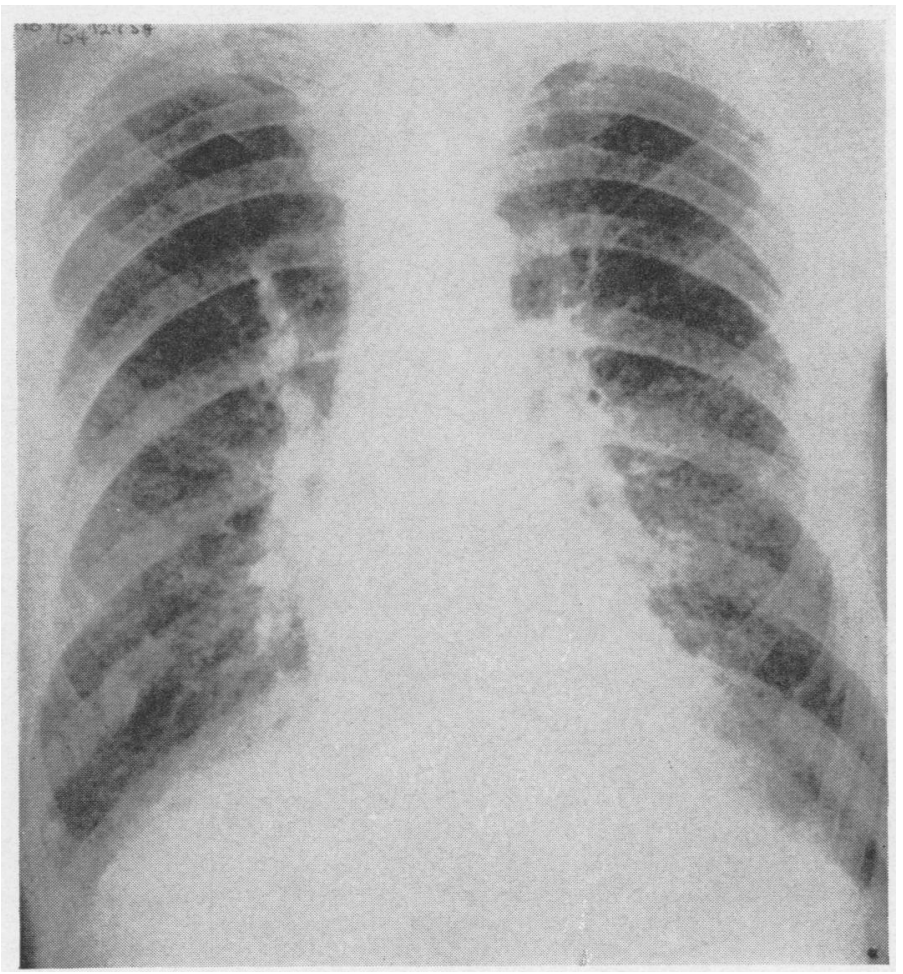

Fig. 2.-Case 5, January 1954, 15 years' exposure. 


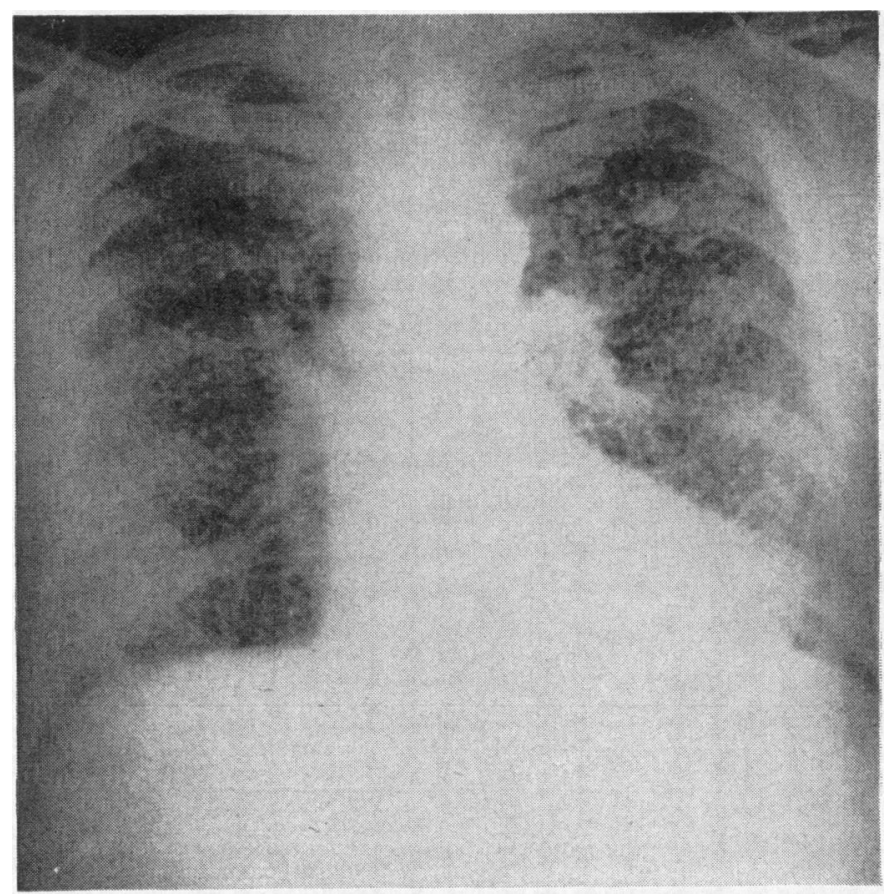

FIG. 3.-Case 6, June 1957, 60 years' exposure.

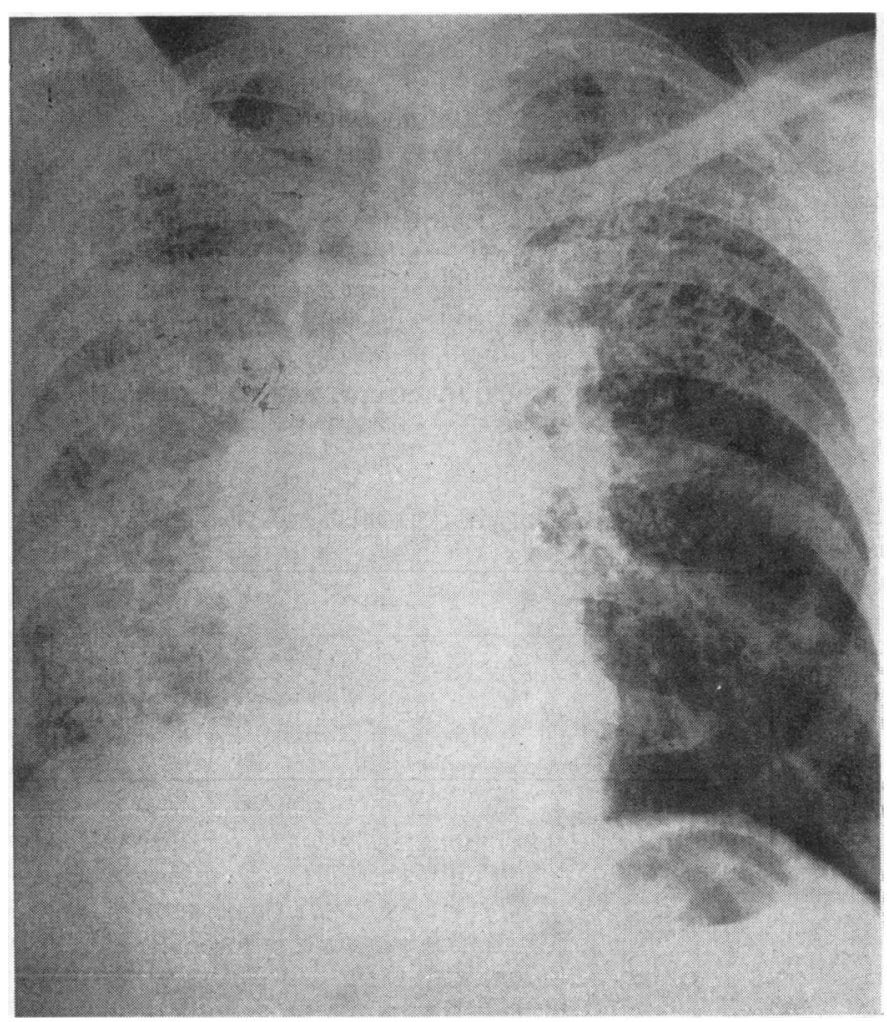

Fig. 4.-Case 7, June 1954, 19 years' exposure. 
zinc chloride fluxes. In the latter processes local exhaust ventilation was provided.

In 1963 he gave no history of illness and nothing abnormal was found on examination.

The report on the chest radiograph taken on August 21, 1963 is as follows: 'Shows an increase of the transverse diameter of the heart and prominent pulmonary vessels. Micro-nodular opacities are scattered over both lung fields, though more profusely in the mid and lower fields. Slight increased translucency is present over the left diaphragm. Classification: $\mathrm{n} 2$ ( + cardiac enlargement).'

Case 5.-W.H. aged 60 had worked as a hearth tinner for 15 years and then as a furnace stoker. He was admitted to hospital in 1954 with a coronary thrombosis. He died in 1961 of carcinoma of the stomach.

The following is a report on the chest radiograph taken on January 12, 1954 (Fig. 2): 'Shows profuse opaque micro-nodular opacities through both lung fields. Extremely opaque hilar shadows. Classification: 3m.'

Case 6.-J.W. aged 72 worked as a hearth tinner for 60 years. In 1957 he gave no history of any illness for 62 years and nothing abnormal was found on clinical examination. He died at home three years later of congestive heart failure.

The report on the chest radiograph taken on June 3, 1957 (Fig. 3) is as follows: 'Shows extremely profuse and very opaque micro-nodular opacities evenly distributed over both lung fields. Both hilar shadows and a larger nodular opacity in the left upper field are extremely opaque. Classification: $\mathrm{m} 3$.'

Case 7.-H.A. aged 63 worked as a hearth tinner for 19 years, then as a bricklayer's labourer for 18 years. In 1943 he started work as a spring hardener and temperer, but after eight years he retired because of ill health. In 1951 he suffered increasing dyspnoea and in 1954 died of cerebral degeneration attributed to a previous head injury.

A chest radiograph taken on June 22, 1954 (Fig. 4) is reported as follows: 'Reveals widening of the superior mediastinum, rotation of the heart, and traction of the trachea to the right. The hilar shadows are very dense and the pulmonary vessels are drawn up. The right lung field is contracted, and both lung fields show a honeycomb appearance, which is more obvious in the right. Very opaque and extremely profuse micro-nodular opacities almost obscure the lung pattern of the right lung; in the left lung these opacities are less profuse and largely confined to the upper and mid fields. A condensation of opaque material is seen in the walls of the cystic spaces. Classification: di.p3 ( + honeycomb lung).'

Post-mortem examination of the lungs showed severe bronchiectasis and bronchiolectasis as well as black dust-pigmented interstitial fibrosis in all areas. The appearances were those of a honeycomb lung.

Microscopy confirmed bronchiectasis and bronchiolectasis. The airways were filled with mucus infiltrated with polymorphs. There was marked squamous hyperplasia and metaplasia of bronchial and bronchiolar epithelium. There was marked peribronchial interstitial fibrosis, and in the space between the fibres there were numerous dust-laden macrophages.

Analysis showed the tin content of wet lung tissue to be $4.7 \%$.

Case 8.-A.H. aged 78 had been a hearth tinner for 61 years until he retired at the age of 75 .

There was no history of ill health until he was admitted to hospital with bronchitis in 1962 . He died in 1963 of reticulo-sarcoma of the pancreas.

The report on a chest radiograph taken on March 31, 1963 (Fig. 5) is as follows: 'Shows prominent pulmonary vessels and very opaque hilar shadows. Very profuse punctate opacities are scattered over both lung fields, and in both upper lobes there are dense confluent opacities. There is a rounded opacity above the right hilum in the superior mediastinum. Classification: p3 (fibrosis at both apices).'

At necropsy carcinomatosis was found with a primary reticulo-sarcoma in the body of the pancreas and secondaries involving the spleen and lymph nodes, with fibrosis in both lungs.

Microscopical examination revealed numerous duct foci showing advanced collagenization. The bronchi contained a large amount of purulent exudate, and there was marked squamous hyperplasia of the lining epithelium. There was confluent centrilobular emphysema. The features were those of a simple pneumoconiosis.

Case 9.-A.T. aged 65 worked for 50 years as a hearth tinner. In 1957 he developed haemoptysis and was found to be suffering from a squamous-cell carcinoma of the upper lobe of the right lung. He died in 1959 of multiple metastases.

A chest radiograph taken on January 3, 1959 was reported on as follows: 'Reveals scoliosis and an unfolded descending aorta. There are scattered micronodular opacities in both lung fields. The hilar glands are very opaque. In the right upper field there is an excavated mass, the walls of which are irregular and the outline somewhat indefinite. Classification: $2 \mathrm{~m}$ (+ excavated neoplasm).'

Case 10.-W.H. aged 52 worked for 38 years as a hearth tinner's labourer. $\mathrm{He}$ died of inanition and pneumonia in 1955. The report on the chest radiograph of that date was: 'Lobar pneumonia in the left lung with multiple nodular opacities throughout both lungs.'

At necropsy there was advanced nodular pneumoconiosis in both lungs with little evidence of fibrosis. There were multiple small lung abscesses in the left lung.

An analysis of both lungs showed $18 \mathrm{~g}$. of tin expressed as the oxide.

\section{Discussion}

The finding of dense opacities without fibrosis associated with opaque hilar shadows in the radio- 


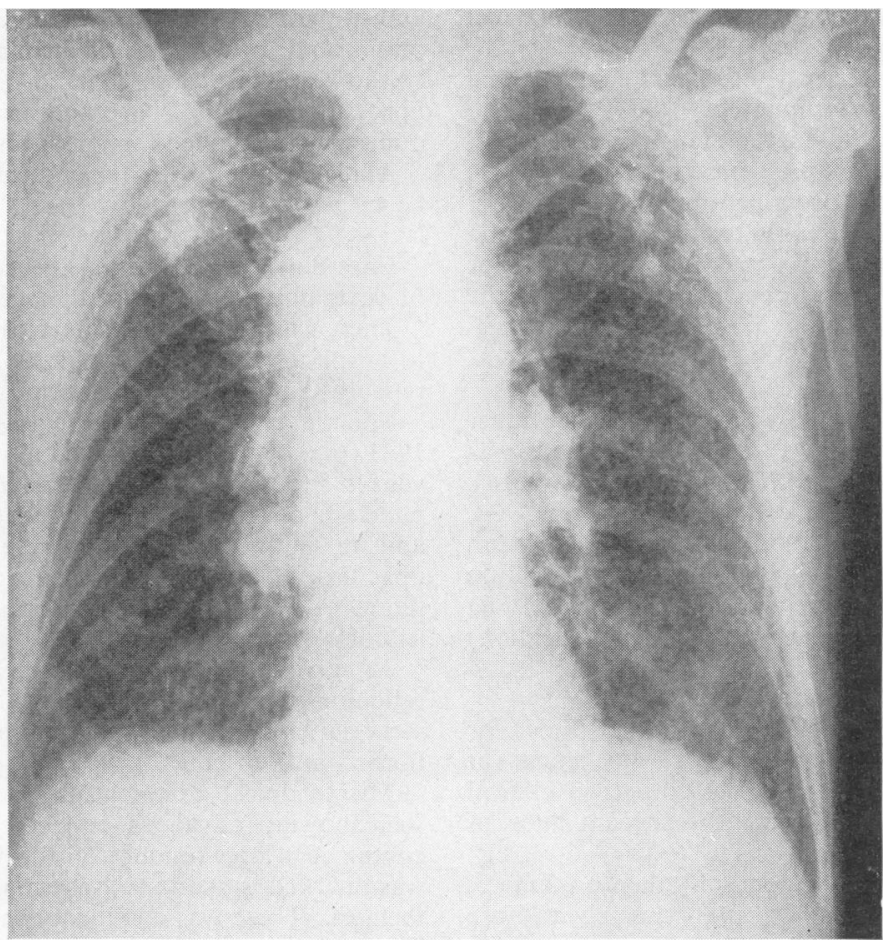

Fig. 5.-Case 8, March 1963, 61 years' exposure.

graphs of 10 hearth tinners suggested a previously unreported source of stannosis.

A noticeable feature clinically was the comparative absence of respiratory disablement in the presence of gross radiological abnormality. In every case there was prolonged exposure to tin similar to that previously described by Robertson and Whitaker (1955). In three cases, however, other pulmonary lesions in association with stannosis were found.

Case 7 was found at necropsy to have a honeycomb lung, and this pathological condition was also described in a previous fatal case of stannosis (Dundon and Hughes, 1950); but no evidence of this condition was found in a series of 121 cases of stannosis reported by Robertson and Whitaker (1955).

Case 8 was found at necrospy to have suffered from a simple pneumoconiosis with fibrosis in addition to stannosis. This condition is known to occur in men exposed to dust in the fettling shops of hollow-ware tinners. It was suggested to us that he might have frequented the fettling and sand-blasting departments, but we are unable to confirm this, and in general the hearth tinners were a discrete working group.

Case 9 developed a carcinoma of the lung.
Ansell (1961) drew attention to three cases of carcinoma of the lung occurring in tin smelters. Robertson (personal communication, 1963) found no evidence of an increased incidence in a 30-year follow-up of 121 tin smelters.

The mechanism by which tin was inhaled requires further consideration in view of the low temperature used in hearth tinning, at which the vapour pressure of tin is of the order of $10^{-20} \mathrm{~mm}$. of mercury (Cooke, personal communication, 1963), and the absence of reports of stannosis in other tinning industries. We consider the production of fume from the use of a chloride flux in the absence of local exhaust ventilation was the causative factor.

In the tin plate industry fume does not now occur. Tallow was first used as a flux. Later the original technique of using zinc chloride fluxes led to complaints of offensive fume (Whymper, 1888), but this complaint was removed by using a palm oil seal on the molten tin (Anderson, Legge, and Duckering, 1907). In hot dip tinning a zinc chloride flux is used, but it is now customary to provide efficient local exhaust ventilation. However, we have seen one case of stannosis from this process when there was no exhaust ventilation.

It is of value to compare hearth tinning with the 
tinning of metal hollow-ware in which a lead-tin mixture was applied with a zinc chloride flux. The utensils were dipped in hydrochloric acid and flux baths, then in a molten alloy bath, and finally wiped with tow. The temperature of the process $\left(275^{\circ} \mathrm{C}\right.$.) was below the melting point of lead $\left(335^{\circ} \mathrm{C}\right.$.). Fumes arose from the alloy during tinning and especially during wiping. Lead poisoning in this industry was investigated in 1893, 1902, and 1907, the special rules made in 1893 being superseded by more stringent regulations in 1907 (Anderson and Legge, 1902; Anderson et al., 1907). Legge stressed the high incidence, the quick onset, and the severity of lead poisoning in this industry. In the first recorded lead-in-air measurements (Legge, 1934), lead and tin were both found in the atmospheres over the tinning baths; it was estimated that a tinner inhaled $0.0143 \mathrm{~g}$. of lead chloride and $0.0070 \mathrm{~g}$. of tin oxide, and a wiper inhaled $0.0402 \mathrm{~g}$. of lead and its compounds and $0.0327 \mathrm{~g}$. of tin and its compounds in a working day.

A survey of the terne plate industry in which a lead-tin alloy was used and where the technique was similar to that of the tin plate industry revealed no cases of lead poisoning. It was therefore deduced that the fume was the cause of lead poisoning in the hollow-ware industry (Anderson et al., 1907). The statutory provision of efficient local exhaust ventilation has been shown to have removed the risk of lead absorption (Rainsford, personal communication 1956) and undoubtedly also the inhalation of leadtin alloy.

We are of the opinion that in the same way as fumes from the zinc chloride process in the hollowware industry produced lead poisoning, so the denser fumes from the ammonium chloride process (Hoare, 1959) in hearth tinning produced stannosis, and the lack of fumes in the manufacture of tin plates and terne plates was the reason for the absence of stannosis and lead poisoning in these industries.

The occurrence of stannosis in hearth tinners is not of historical interest only since the process is still carried out, and in the absence of knowledge that an abnormal radiograph is that of a tinner or that stannosis can occur in tinners, silicosis, mycosis, or a less benign pneumoconiosis may, as in the past, be diagnosed.

We are greatly indebted to Dr. A. J. Robertson for his help and advice, to Dr. J. C. Ford and Dr. W. W. Jones for their assistance, to Dr. A. O. Bech for the radiograph reports, to Dr. D. Rivers for the pathological reports, to Dr. M. A. Cooke for information on the properties of tin, to Dr. J. J. Hutchinson for details of case 4, and to Dr. T. A. Lloyd Davies for encouragment.

\section{REFERENCES}

Anderson, A. M., and Legge, T. M. (1902). Annual Report for 1902 of Chief Inspector of Factories and Workshops, p. 296. H.M. Stationery Office, London.

Stationery Office, and Duckering, G.

Ansell, G. (1961). Lancet, 1, 1225.

Barták, F., Tomecka, M., and Tomičk, O. (1948). Čas. Lék. čes., 87,915 .

Beintker, E (1944). Reichsarbeitsblatt, 3, 37.

Browning, E. (1961). Toxicity of Industrial Metals, p. 288. Butterworths, London.

Cutter, H. C., Faller, W. W., Stocklen, J. B., and Wilson, W. L. (1949).' J. industr. Hyg., 31, 139.

Dundon, C. C., and Hughes, J. P. (1950). Amer. J. Roentgenol., 63, 797.

Hedges, E. S. (1960). Tin and its Alloys, pp. 1-15. Arnold, London. Hoare, W. E. (1959). Hot-tinning, p. 64. W.M. Ltd., London.

Jope, E. M. (1956). Oxoniensia, 21, 35.

Legge, T. M. (1934). Industrial Maladies, p. 51. Oxford University Press, London.

Meeting of Experts on the International Classification of Radiographs of the Pneumoconioses, Geneva (1958). Occup. Safety Hlth, of the

Oyanguren, H., Haddad, R., and Masss, H. (1958). Industr. Med. Surg., 27, 427.

Pendergrass, E. P., and Pryde, A. W. (1948). J. industr. Hyg., 30, 119 Robertson, A. J., and Whitaker, P. H. (1955). J. Fac. Radiol. (Lond.) 6, 224.

Rivers, D., Nagelschmidt, G., and Duncumb, P. (1961). Lancet, 1, 1089 .

Spencer, G. E., and Wycoff, W. C. (1954). Arch. industr. Hyg., 10, 295 Whymper, F. H. (1888), Report of the Chief Inspector of Factories and Workshops, pp. 45-59. H.M. Stationery Office, London. 